\title{
ERK1/2 activation is required for resveratrol- induced apoptosis in MDA-MB-231 cells
}

\author{
THANH-HUNG NGUYEN ${ }^{1,2}$, FATIMAH B. MUSTAFA ${ }^{1,2}$, SHAZIB PERVAIZ $^{1,3,4,5}$, \\ FLORENCE S.P.NG and LINA H.K. LIM ${ }^{1,2}$

\begin{abstract}
${ }^{1}$ Department of Physiology, ${ }^{2}$ NUS Immunology Program, ${ }^{3}$ NUS Graduate School for Integrative Sciences and Engineering, Yong Loo Lin School of Medicine, National University of Singapore, 28 Medical Drive, Singapore 117456; ${ }^{4}$ Singapore-MIT Alliance; ${ }^{5}$ Duke-NUS Graduate Medical School, Singapore
\end{abstract}

Received November 26, 2007; Accepted January 25, 2008

\begin{abstract}
Resveratrol (RSVL), a phytoalexin found in abundance in grapes and other grape-related products, has been shown to be antiproliferative and protective against various types of cancers, including breast cancer. However, the precise underlying mechanisms are not well understood. In this study, we show that treatment with RSVL induces growth inhibition and apoptosis in a highly invasive and metastatic breast cancer cell line MDA-MB-231. Cleavage of caspase-3 and PARP and fragmentation of DNA were observed following exposure to RSVL. Co-treatment with pan-caspase inhibitor completely prevents cell death induced by RSVL. We found that RSVL-induced apoptosis correlates with sustained activation of ERK1/2 and suppression of Bcl-2 expression. Inhibition of ERK1/2 activation by its specific inhibitor or small interfering RNA reverses the effect of RSVL on Bcl-2 suppression and inhibits apoptosis, while overexpression of MEK1, which is directly upstream of both ERK1 and ERK2, enhances apoptosis induced by RSVL. Moreover, ERK1/2 was found to act upstream of caspase-3 to induce apoptosis, while it was not directly involved in caspase-3 cleavage. The other closely related MAPK members, p38 and JNK are not involved in apoptosis induced by RSVL in MDA-MB-231 cells. These results suggest that activation of ERK1/2 is required for RSVL-induced apoptosis in MDA-MB-231 cells.
\end{abstract}

\section{Introduction}

Breast cancer is one of the most common malignancies and a frequent cause of death in women worldwide (1). Although early stage breast cancer is well managed by surgery and

Correspondence to: Dr Lina H.K. Lim, Inflammation and Cancer Lab, Department of Physiology, Yong Loo Lin School of Medicine, National University of Singapore, 28 Medical Drive, Singapore 117456

E-mail: linalim@nus.edu.sg

Key words: apoptosis, extracellular signal regulated kinase 1/2, Bcl-2, metastasis conventional treatments, there are few curative options beyond early detection. The metastasis rate found at presentation remains high and many of those without initial apparent clinical metastasis ultimately develop distant metastases (2). Metastasis has always been the most serious turning point of breast cancer since the majority of women with metastasis will die of their disease (3). Therefore, new treatments for breast cancer, especially invasive tumors, are needed.

Naturally occurring compounds have recently attracted attention since nutrition and diet have been found to influence the development and progress of breast cancer (4). A number of natural substances, particularly those existing highly in our daily diet, have been reported to prevent cancer development and inhibit cell growth $(5,6)$. Resveratrol (RSVL) is one such dietary natural compound that has chemopreventive properties and inhibitory effects on cancer cells both in vitro and in vivo (7-9; reviewed in ref. 10).

RSVL, found abundantly in grapes and grape-related products, was shown to inhibit cancer initiation, promotion and progression (7). As it is structurally similar to diethylstilbestrol, many studies have suggested that RSVL binds to and inhibits estrogen receptor $(\mathrm{ER}) \alpha(11,12)$. However, RSVL has been shown to have growth inhibitory effects on $\mathrm{ER} \alpha$ negative cell lines and blocking ER $\alpha$ does not prevent its anti-proliferative action, suggesting that antagonism of $\mathrm{ER} \alpha$ is not a unique mechanism for its growth inhibitory effects (13). Although it has been shown RSVL exerts its inhibitory effects by inducing cell cycle arrest and apoptosis in a variety of cancer cell lines and more importantly in animal models of carcinogenesis $(7,8,14-16)$, the mechanisms by which RSVL exerts its anti-tumor effects on highly metastatic and unresponsive breast cancer cells such as MDA-MB-231 (MDA231) are not fully understood.

Recent studies suggested that signal transduction pathways via ERK signaling play important roles in the formation, progression and metastasis of breast cancer $(17,18)$. The Ras/MEK/ERK pathway regulates mammalian cell growth by conveying extracellular signals to the nuclear via a cascade of specific phosphorylation events which begin with Ras activation and center on ERK activation (18-20). Aberrant signaling through the ERK pathway could promote cell 
immortalization via telomerase induction, growth factorindependent proliferation by cell cycle activation, invasion and metastasis via stimulation of cellular motility and extracellular matrix remodeling $(17,20)$. Highly metastatic breast cancer cell lines, such as MDA231 and MDA-MB-468, have constitutively higher ERK activity when compared to the non-invasive MCF-7 breast cancer cells and enforced induction of ERK activation enhances the mobility and invasion of these cells (18). Interestingly, recent studies implicate that activation of ERK may play a role in cancer treatment (reviewed in ref. 21). However, the available data are contradictory. While inhibition of ERK1/2 signaling leads to cell death, many recent studies suggest that ERK activation induced by anticancer drugs might be required for growth inhibition and apoptosis (22-24), prompting us to investigate the role of ERK activation in cell death induced by RSVL in the MDA231 metastatic breast cancer cells.

Targeting apoptosis appears to be a promising choice in cancer treatment. Regulation of apoptosis is a complex process involving many cellular genes, including $\mathrm{Bcl}-2$ and Bcl-2 related family members such as Bcl-XL, Bax and $\mathrm{Bad}$. The balance between anti-apoptotic and pro-apoptotic proteins of the Bcl-2 family has been shown to play a critical role in maintaining cell survival. ERK activity has long known to be pro-survival because of its ability to inhibit pro-apoptotic proteins (25). However, other studies suggest ERK could also have possible pro-apoptotic properties upon activation following drug treatment by promoting the activities of proapoptotic proteins such as p53 and Bak (reviewed in ref. 21).

In this study, we show that RSVL inhibits cell growth and proliferation by mainly causing apoptosis in the ER $\alpha$ negative, highly metastatic breast cancer cell line MDA231. RSVLinduced apoptosis correlates with the activation of ERK1/2 and suppression of Bcl-2 expression. Inhibition of ERK activity by small molecule inhibitor or small interfering RNAs almost completely inhibits apoptosis and reverses Bcl-2 suppression, while enforced activation of ERK renders cells more sensitive to apoptosis induced by RSVL. Thus this is the first demonstration that ERK1/2 is required for apoptosis induced by RSVL in MDA231 cells.

\section{Materials and methods}

Reagents. Resveratrol (RSVL), 3-(4, 5-dimethylthiazol-2-yl)2,5-diphenyltetrazolium bromide (MTT), 4,6-diamidino-2phenylindole (DAPI), bovine cytochrome c and dATP were purchased from Sigma-Aldrich Co. (St. Louis, MO, USA). MEK1/2 specific inhibitor UO126 were purchased from Cell Signaling Technology (Beverly, MA, USA). The pan-caspase inhibitor (Z-VAD-FMK) and p38 MAPK kinase inhibitor SB203580 were obtained from Calbiochem (La Jolla, CA, USA). c-Jun N-terminal kinase specific inhibitor SP600125 was purchased from AG Scientific (San Diego, CA, USA). RSVL, kinase and Z-VAD-FMK inhibitors were dissolved in dimethylsulfoxide (DMSO) with final concentration of DMSO used for treatment being $0.1 \%$. They were stored frozen under light-protected conditions at $-20^{\circ} \mathrm{C}$.

Antibodies against Hemagglutin (HA)-Tag (6E2), p38 MAPK, phospho-p38 (Thr180/Tyr182), JNK, phospho-JNK
(Thr183/Tyr185), phospho-ERK1/2 (Thr202/Tyr204), phospho-Akt-1 (Thr308 and Ser473), cleaved PARP, cleaved caspase-3, Bax, Bim, Bad, Bcl-2 (human specific) and phospho-Bcl-2 Ser70 were purchased from Cell Signaling (Beverly, MA, USA). Antibodies against $\alpha$-tubulin, $\beta$-actin, PI-3K, ERK1 and Akt-1 were obtained from Santa Cruz Biotechnology (Santa Cruz, CA, USA). Horseradish peroxidase-conjugated rabbit anti-mouse and anti-rabbit secondary antibodies were purchased from Pierce (Rockford, IL, USA). Chemiluminescent Reagent Plus detection system was supplied by PerkinElmer Life Sciences Inc. (Boston, MA, USA).

The constitutively expressed MEK1 construct, pMCLHA-MEK1 (R4F) (17), was kindly provided by Professor Natalie Ahn (University of Colorado, Boulder, CO, USA). Pre-designed ON-TARGET plus SiRNA duplexes against ERK1 and ERK2, control (scrambled) SiRNA duplexes and Dhamarfect transfection reagent were purchased from Dhamarcon, Inc. (Lafayette, CO, USA). All ERK1, ERK2 and scrambled SiRNAs represented a mixture of four distinct RNA duplexes (smart pool). Hygromycin was purchased from Invitrogen (Carlsbad, CA, USA). RNeasy Protect Mini Kit, One-Step RT-PCR kit and SuperFect Transfection Reagent was obtained from Qiagen Inc. (Germany).

Cell culture and drug treatment. Human MDA-MB-231 (MDA231) cell line was obtained from ATCC and cultured in DMEM (Invitrogen) supplemented with $10 \%$ fetal bovine serum (FBS, Hyclone) and $2 \mathrm{mM}$ L-glutamine (growth medium) at $37^{\circ} \mathrm{C}$ in a $5 \% \mathrm{CO}_{2}$ incubator. It has been documented that MDA231 cells are ER $\alpha$ negative, highly invasive and metastatic, express mutant-inactive p53, and have high activity of MAPK $(16,18)$.

For SiRNA and stable transfection, 200,000 cells were seeded in 6-well plate $24 \mathrm{~h}$, serum starved for $6 \mathrm{~h}$ before transfection. For treatment with RSVL and inhibitors, cells were seeded in growth medium at the same initial density, and were allowed to adhere and grow overnight (70-80\% confluence). Cells were washed once with serum-free DMEM media (SFM) and serum starved for 6 hours (h) before treatment with indicated concentrations of RSVL in SFM. Control cells were treated with vehicle $(0.1 \%$ DMSO). For combined treatment, inhibitors were added $1 \mathrm{~h}$ before RSVL.

Determination of cell growth rate and cell viability. The cell growth rate was determined by qualitative measurement of the conversion of 3-(4, 5-dimethylthiazol-2-yl)-2,5-diphenyltetrazolium bromide to a water-insoluble formazan by the mitochondrial dehydrogenase enzyme in metabolically active cells. Cell growth rate was determined at 24 and $48 \mathrm{~h}$ after treatment using MTT assay as previously described (26). Cell viability was determined using trypan blue $[0.4 \%$ in phosphate-buffer saline (PBS)] exclusion assay. Briefly, after 24 and $48 \mathrm{~h}$ of treatment, floating cells were collected by centrifuging the media. Adhered cells were trypsinized and pooled together with floating cells. An aliquot of suspension cells was mixed with an equal volume of trypan blue and counted by a light microscope. Dead cells were defined as those stained blue with the dye. 
Analysis of nuclear staining with DAPI. Cells were treated with vehicle, 1,10 and $50 \mu \mathrm{M}$ of RSVL for $24 \mathrm{~h}$. After treatment, cells were fixed with $3.7 \%$ formalin at room temperature for $1 \mathrm{~h}$, washed with PBS and stained with 4,6-diamidino-2phenylindole (DAPI, $1 \mu \mathrm{g} / \mathrm{ml}$ in methanol) for $5 \mathrm{~min}$ at $37^{\circ} \mathrm{C}$. Cells were washed, examined and photographed using a Leica DC300F fluorescence microscope equipped with a UV light filter. Apoptotic cells were defined on the basis of chromatin condensation and nuclear fragmentation (bead-like formation). Apoptotic percentage was obtained by counting the number of apoptotic cells among at least 500 cells/region. The data were expressed as the mean $\pm \mathrm{SD}$.

Western blot analysis. Treated cells were harvested at indicated times and lysed in a lysis buffer containing $75 \mathrm{mM} \mathrm{NaCl}$, $10 \mathrm{mM}$ Tris $(\mathrm{HCl}), 1 \mathrm{mM}$ EDTA, $0.5 \%$ NP40, $0.5 \%$ Triton$\mathrm{X}-100,1 \mu \mathrm{g} / \mathrm{ml}$ leupeptin, $1 \mu \mathrm{g} / \mathrm{ml}$ aprotinin, $1 \mu \mathrm{M}$ phenylmethylsulfonyl fluoride (PMSF), $1 \mathrm{mM} \mathrm{Na}_{3} \mathrm{VO}_{4}$ and protease inhibitor cocktail (Pierce Biotechnology). Protein concentration was determined by the method of Bradford using protein assay kit (Bio-Rad). Proteins $(30 \mu \mathrm{g})$ per sample were subjected to Western blot analysis. Blots were incubated with the antibodies specific for either cleaved caspase-3, cleaved PARP, phopho-ERK1/2 (Thr202/Tyr204), ERK1/2, phosphoAkt-1 (Thr308 and Ser473), Akt-1, phospho-p38 (Thr180/ Tyr182), p38, phospho-JNK (Thr183/Tyr185), JNK, phosphoBad (Ser112 and Ser136), Bad, Bax, phospho-Bcl2, Bcl-2, truncated Bid, Bim, Bcl-XL, cytochrome c, PI-3K and 1:7500 horseradish peroxidase-conjugated rabbit anti-mouse or mouse anti-rabbit secondary antibodies (Pierce Biotechno$\log y)$. All the primary antibodies were used at the final concentration of $1 \mu \mathrm{g} / \mathrm{ml}$. To detect phosphorylated proteins, the same blots were probed with phospho-specific antibodies, stripped and reprobed with antibodies against total proteins. All blots were incubated with mouse antibody against $B$-actin or $\alpha$-tubulin to confirm equal protein loading. Bands were visualized with a Chemiluminescent Reagent Plus detection system as described by the manufacturer. For quantitation analysis of Western blotting, the sum of the density of bands corresponding to protein blotting with the antibody under study was calculated and normalized to the amount of B-actin using ImageJ software (National Institute of Health, USA). After normalisation to $B$-actin, the expression level of proteins under study between the samples was expressed in the fold changes.

SiRNA transfection. Pre-designed ON-TARGET plus SiRNA duplexes against ERK1/2 and control (scrambled) SiRNA duplexes were purchased from Dhamarcon, Inc. (Lafayette). Both scrambled and ERK1/2 SiRNAs represented a mixture of four distinct RNA duplexes (Smart pool, Dhamarcon). Cells were seeded in 6-well plates and transfected with $100 \mathrm{nM}$ of SiRNAs using DhamarFECT reagent in antibiotic-free conditions according to the manufacturer's instructions. At $6 \mathrm{~h}$ after transfection, cells were washed by DMEM media and supplemented with fresh DMEM containing 5\% FCS. The cells were incubated $24 \mathrm{~h}$ prior to treatment. The transfected cells were then treated with either vehicle or indicated concentrations of RSVL for $24 \mathrm{~h}$ and harvested for Western blot analysis.
RNA extraction and reverse transcriptase PCR. Total RNA was prepared using Rneasy Protect Mini Kit following the manufacturer's instructions. Total RNA (500 ng) was used as template for onestep reverse transcriptase PCR (RT-PCR) using Onestep RT-PCR kit (Qiagen), adopting the procedure recommended by the manufacturer, using the following primers for Bcl-2: 5'-GGATTGTGGCCTTCTTTGAG-3' (forward) and 5-TCACTTGTGGCCCAGATAGG-3' (reverse). A RT-PCR was run at $50^{\circ} \mathrm{C}$ for $30 \mathrm{~min}$ for reverse transcription and $95^{\circ} \mathrm{C}$ for $15 \mathrm{~min}$ for initial denaturation, followed by various cycles of $94^{\circ} \mathrm{C}$ for $45 \mathrm{sec}, 55^{\circ} \mathrm{C}$ for 45 sec and $72^{\circ} \mathrm{C}$ for $1 \mathrm{~min}$ finally at $72^{\circ} \mathrm{C}$ for $10 \mathrm{~min}$. To optimize the number of cycles for RT-PCR to prevent an amplification plateau, total RNA was amplified through 25, 27, 29, 31, and 33 cycles. The optimal cycles for detection of the bcl-2 transcript were 31. A pair of GAPDH primers, AACACA GTCCATGCCATCAC (forward) and TCCACCACC CTGTTGCTGTA (reverse) was used to amplify a 400-bp fragment of GAPDH gene ( 24 cycles) for normalization. The amplified products were separated on a $1.5 \%$ agarose gel.

Preparation of S-100 fraction and induction of in vitro apoptosis. Cytoplasmic fractions (designated S-100) were prepared with protection of mitochondria as previously described (27). Briefly, cells were harvested after treatment by trypsinisation and centrifugation at $750 \mathrm{~g}$ for $10 \mathrm{~min}$ at $4^{\circ} \mathrm{C}$. Cell pellets were washed once with ice-cold PBS and resuspended in lysis buffer containing $20 \mathrm{mM}$ HEPES-KOH, $\mathrm{pH} 7.5,10 \mathrm{mM} \mathrm{KCl}$, and $1.5 \mathrm{mM} \mathrm{MgCl}_{2}, 1 \mathrm{mM}$ sodium EDTA, $1 \mathrm{mM}$ EGTA, $1 \mathrm{mM}$ dithiothreitol, $0.1 \mathrm{mM}$ PMSF and $250 \mathrm{mM}$ sucrose. The cells were incubated on ice for $15 \mathrm{~min}$, followed by shearing 10 times with a $26-\mathrm{G}$ needle. The homogenates were centrifuged at $100,000 \mathrm{~g}$ per minute for $1 \mathrm{~h}$ and the supernatants were collected as S-100 fractions. To detect the release of cytochrome c into the cytosol and caspase-3 cleavage, $10 \mu \mathrm{g}$ of proteins per sample were subjected to Western blot analysis. The blots were incubated with antibodies against cytochrome c and cleaved caspase- 3 . To induce in vitro apoptosis, $50 \mu \mathrm{g}$ of S-100 were incubated with $1 \mathrm{mM}$ dATP and $0.3 \mu \mathrm{g}$ of cytochrome $\mathrm{c}$ at $30^{\circ} \mathrm{C}$ for $30 \mathrm{~min}$ in a water bath and the samples were analyzed by Western blotting to detect caspase- 3 cleavage.

Stable transfection. MDA231 cells were seeded in 6-well plates and transfected with $4 \mu \mathrm{g}$ of either pMCL-HA-MEK1 or empty vector pMCL (mock) and $10 \mu \mathrm{l}$ of SuperFect reagent per well as described by the manufacturer. The MEK1 construct was generated by mutagenesis of Ser218 and Ser222 residues to glutamate and aspartate, respectively, in addition to $\mathrm{N}$-terminal deletion of amino acid residues 32 to 51 (17). Three hours after transfection, cells were washed once with PBS and allowed to grow in normal growth media for $48 \mathrm{~h}$. Cells were then sub-cultured in a ratio of 1:40 in growth medium containing $250 \mu \mathrm{g} / \mathrm{ml}$ of Hygromycin to select for resistant clones. After 2 weeks of selection, positive clones were isolated and analyzed for phospho-ERK1/2, MEK1 and HA expression. The clones R4F12 and R4F18, which expressed high levels of MEK1 (confirmed by phosphoERK1/2 and HA antibodies), were selected and expanded for further study. The sensitivity of mock and MEK1 transfected clones to RSVL was then compared. 

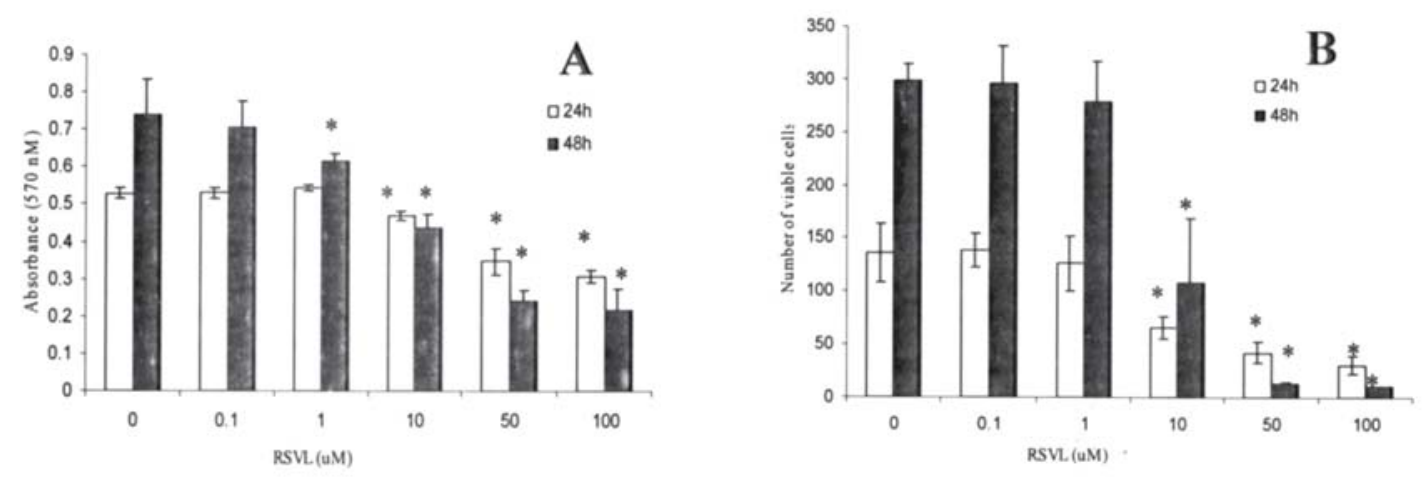
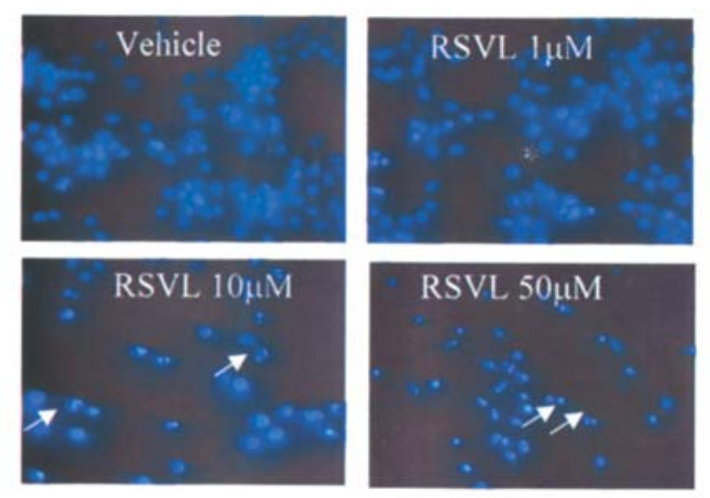

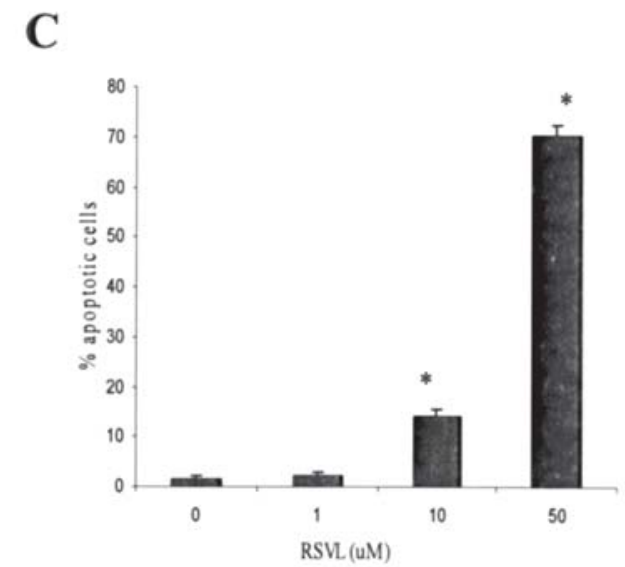

Figure 1. RSVL-mediated effects on cell viability and apotosis. Cell viability was determined by MTT (A) and trypan blue exclusion assays (B). MDA231 cells were grown and treated with assay media containing either vehicle or indicated doses of RSV for 24 and $48 \mathrm{~h}$ as described in Materials and methods. Experiments were performed in triplicate. The results indicate the mean value \pm SD of the triplicate of each group of treatment. Apoptotic cell death was assessed through DNA fragmentation using nuclear staining with DAPI (C). Cells were treated with vehicle, 1,10 , and $50 \mu \mathrm{M}$ for $24 \mathrm{~h}$, fixed and stained as described in Materials and methods. Stained cells were visualized under a fluorescent microscope (x200). Undergoing apoptotic cells present chromatin condensation and nuclear fragmentation (some pointed by arrows). The rate of apoptosis expressed as percentage of total cells. ${ }^{*} \mathrm{p}<0.01 \mathrm{when}$ compared with vehicle control as determined by ANOVA test. Representative graphs and images from three different experiments with similar results are shown.

Statistical analysis. Each experiment was performed at least 3 times. Statistical significances between groups were determined by ANOVA test. A $p<0.05$ was considered significant.

\section{Results}

To investigate if RSVL had any growth inhibitory activity against highly metastatic MDA231 breast cancer cells, cells were treated with $0.1,1,10,50$ and $100 \mu \mathrm{M}$ of RSVL for 24 and $48 \mathrm{~h}$. Cell proliferation rate and cell viability were assessed by MTT and trypan blue exclusion assays. RSVL induced a concentration-dependent reduction in cell viability and proliferation, which was maximal at 10-100 $\mu \mathrm{M}$ (Fig. 1). At $10 \mu \mathrm{M}, 20 \pm 3.4 \%$ and $40 \pm 4.1 \%$ reductions in cell proliferation were observed at 24 and $48 \mathrm{~h}$, respectively, as assessed by MTT assay (Fig. 1A). Trypan blue exclusion assay, which gives a direct count of cells that exclude trypan blue dye (including apoptotic cells), shows a more significant and clearer effect on cell viability; $50 \pm 3.4 \%$ and $69 \pm 3.1 \%$ reductions in cell viability were observed at 24 and $48 \mathrm{~h}$, respectively (Fig. 1B). A significant reduction in cell proliferation and viability was observed as early as $24 \mathrm{~h}$ after treatment $(\mathrm{p}<0.01)$. The maximal effects were seen at higher concentrations of RSVL, where almost all cells were dead after $48 \mathrm{~h}$. At low concentrations from 0.1-1 $\mu \mathrm{M}$, RSVL has no significant effect on cell viability and proliferation. Concentrations of 50 and $100 \mu \mathrm{M}$ of RSVL showed an almost equal inhibitory effect on cell growth. 10 and $50 \mu \mathrm{M}$ concentrations of RSVL were chosen for subsequent experiments.

To determine if RSVL inhibits cell proliferation and viability by inducing apoptosis in MDA231 cells, DNAspecific fluorescent DAPI staining was performed. Morphological apoptotic features were characterized by condensed chromatin and fragmented nuclei. Apoptotic cells were indeed detected in RSVL-treated cells. Vehicle and $1 \mu \mathrm{M}$ of RSVL treated cells exhibited round nuclei with well-distributed chromatin while apoptotic cells were observed with condensed chromatin and fragmented DNA after $24 \mathrm{~h}$ exposure to RSVL. RSVL significantly induced apoptosis at $10 \mu \mathrm{M}$ $(14.2 \pm 1.3 \%)$ and $50 \mu \mathrm{M}(70.2 \pm 2.1 \%)(\mathrm{p}<0.01)$ (Fig. 1C).

To examine if the apoptotosis machinery is activated by RSVL treatment, we used specific antibodies against cleaved caspase-3 and cleaved PARP. RSVL induced the cleavage of caspase-3 and PARP in a dose-dependent manner, where the 17 and $20 \mathrm{kDa}$ cleaved caspase- 3 fragments and $89 \mathrm{kDa}$ cleaved PARP product (Fig. 2A) were detected in samples treated with 


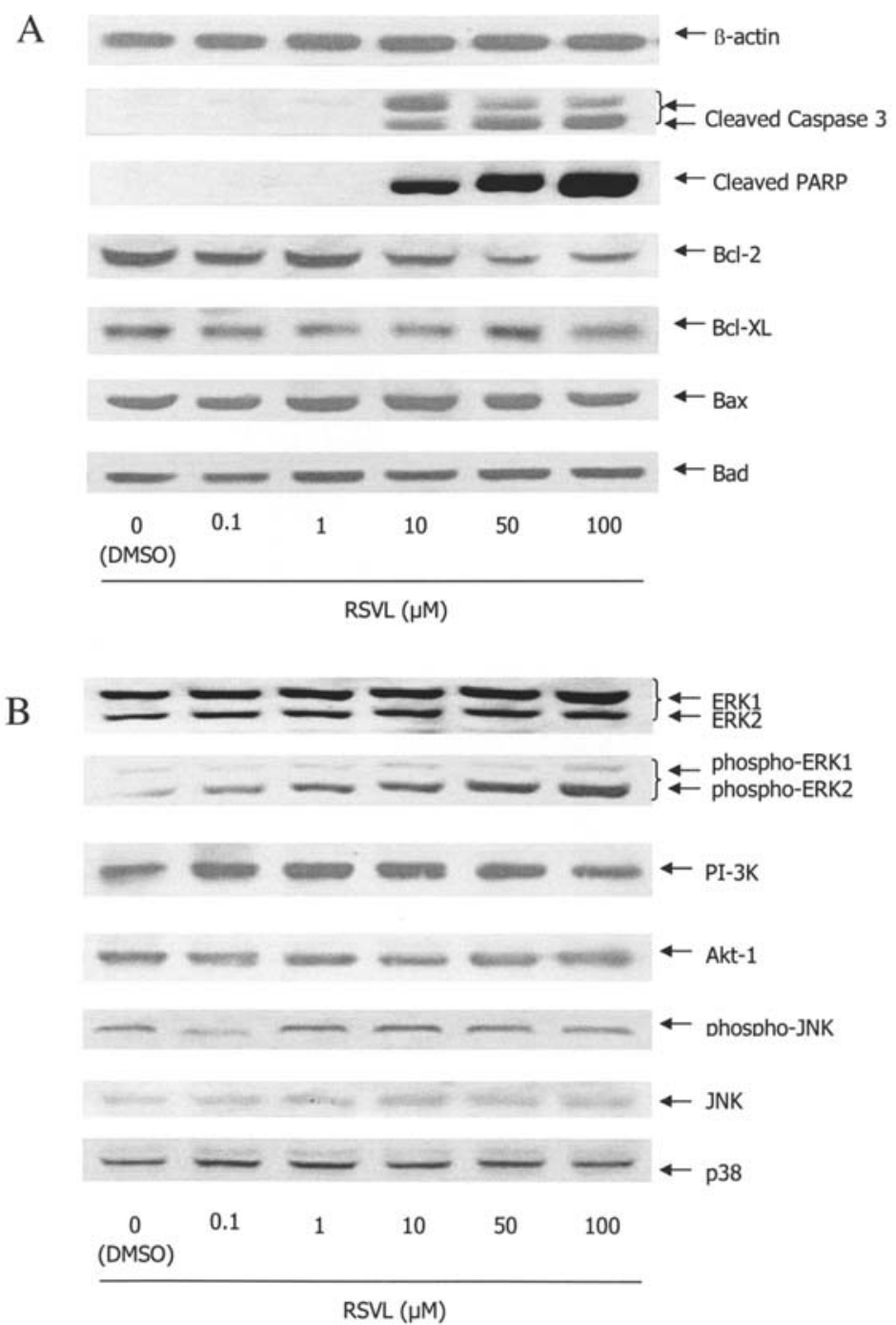

Figure 2. Expression of apoptosis-related proteins and signaling molecules in response to RSVL treatment. MDA231 cells were cultured and treated with vehicle or indicated concentrations of RSVL for $24 \mathrm{~h}$. Cells were harvested and lysed for Western blot analysis as described in Materials and methods. Blots were probed with specific antibodies against (A) apoptosis-related proteins (cleaved caspase-3, PARP, Bcl-2, Bcl-XL, Bax, Bad), or (B) signaling molecules (phospho-ERK1/2, ERK1/2, PI-3K (p85 subunit), Akt-1, phospho-JNK, JNK and p38/MAPK). Phospho-Akt-1 (Ser 473 and Thr308) and phospho-p38 MAPK (Thr180/Tyr182) were undetectable under the experiment conditions. Representative blots of three experiments with similar results are shown.

10,50 and $100 \mu \mathrm{M}$ of RSVL. The data indicate that RSVL activates caspase-3 and further confirms the observation of DNA morphological changes after RSVL treatment.

As programmed cell death in mammalian cells has been shown to be regulated by the balance of proapoptotic proteins such as Bad, Bax and anti-apoptotic proteins like Bcl-2 and Bcl-XL (28), we determined if RSVL-induced apoptosis in MDA231 cells was also regulated by these proteins. As shown in Fig. 2A, no significant change in the expression of Bcl-XL, Bax and Bad was observed following RSVL exposure. We also observed that Bad was not phosphorylated at Ser112 and Ser136 in MDA231 cells using anti-phospho-specific antibodies (data not shown). However, treatment of RSVL significantly suppressed Bcl-2 expression in a dose-dependent manner, suggesting that the suppression of Bcl-2 might be responsible for cell death induced by RSVL.

The Raf/MEK/ERK signaling pathway has been shown to play important roles in cell invasion and metastasis $(18,20)$, but activation of this pathway has also been implicated in the response of cancer cells to drug treatment (reviewed in ref. 21). RSVL has recently been shown to activate ERK signaling in breast cancer cells through a receptor within integrin $\alpha \mathrm{VB3}$ (29). We wished to investigate if RSVL-induced apoptosis was also mediated by the Raf/MEK/ERK pathway in highly metastatic MDA231 cells. Treatment with RSVL up-regulated phosphorylated ERK1/2 (mainly ERK2) in a dose-dependent manner. Interestingly, the increase of phosphorylated ERK1/2 was observed concurrently with cleavage of caspase- 3 and PARP (Fig. 2A). The other two main members of MAPK family, JNK and p38 MAPK were also investigated. As shown in Fig. 2B, there were no clear changes in the expression and activation of these kinases and phospho-p38 MAPK was not detectable under the experimental conditions (data not shown), suggesting that JNK and p38 MAPK may not be activated by RSVL in MDA231 cells.

Since RSVL has been reported to inhibit Akt signaling in prostate cancer cell line LnCap (30), we studied if RSVL has any effect on the PI-3K/Akt pathway in MDA231 cells. As 


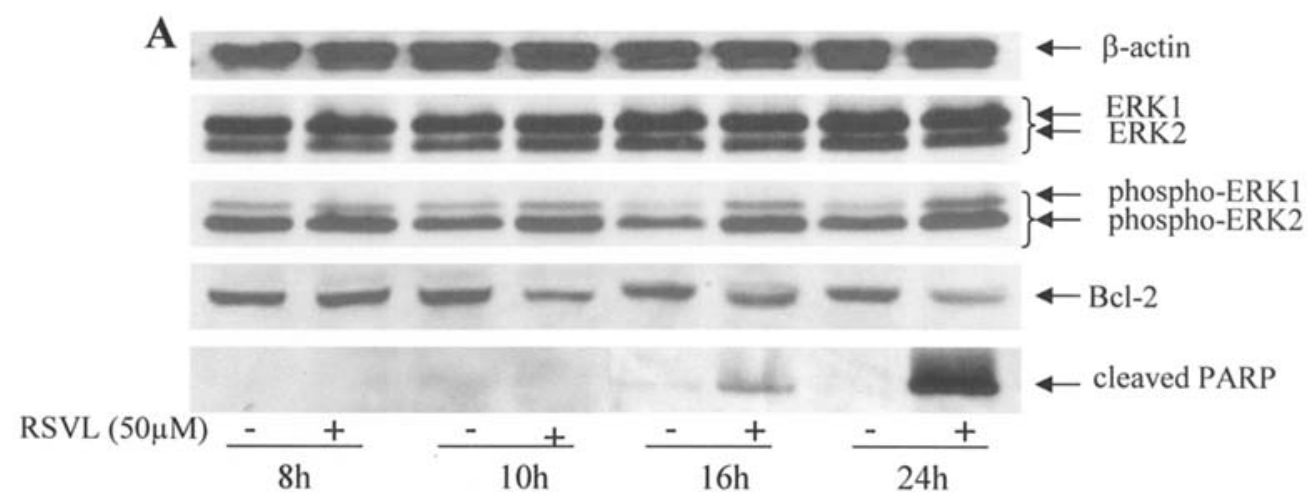

B

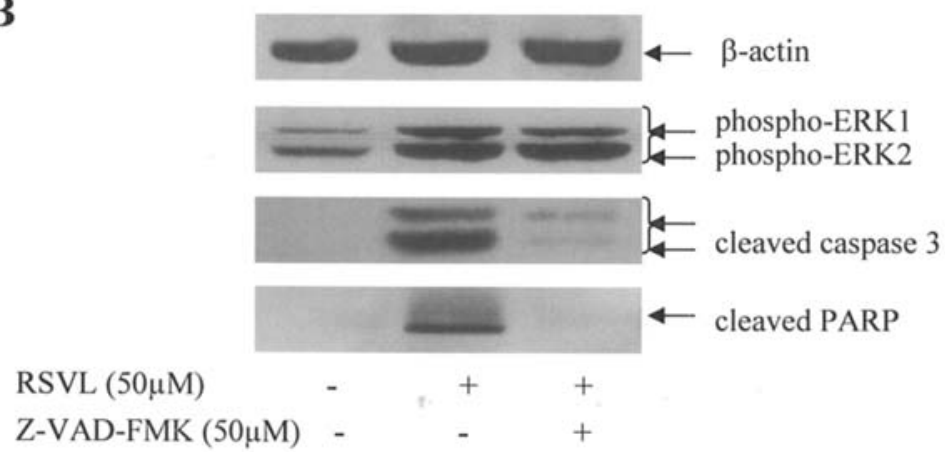

Figure 3. Time course and apoptosis induced by RSVL in MDA231 cells. A, Time-dependent phosphorylation of ERK1/2 and effects of RSVL on PARP cleavage and Bcl-2 expression. Cells were cultured and treated with either vehicle or $50 \mu \mathrm{M}$ of RSVL for indicated times. Cells were harvested and lysed for Western blot analysis as described in Materials and methods. The blots were probed with specific antibodies against phospho-ERK1/2, ERK1/2, cleaved PARP and Bcl-2. The blots represented the time-points that significant change of phospho-ERK1/2 was observed. B, Effect of Z-VAD-FMK on RSVLinduced apoptosis. Cells were treated with either vehicle or $50 \mu \mathrm{M}$ of RSVL or combination of $50 \mu \mathrm{M}$ of Z-VAD-FMK and $50 \mu \mathrm{M}$ of RSVL for $24 \mathrm{~h}$. Cells were harvested and lysed for Western blot analysis. Blots were probed with antibodies against phospho-ERK1/2, cleaved caspase-3 and cleaved PARP. Representative blots of three experiments with similar results are shown.

shown in Fig. 2B, RSVL did not produce a significant effect on the expression level of the $\mathrm{p} 85$ subunit of PI-3 kinase. The same blot was probed with antibodies against phosphorylated Akt-1 (Ser473 and Thr308) showing that these phosphorylation sites of Akt-1 are undetectable under the experiment conditions (data not shown) and no significant change in the expression of Akt-1 was observed. The data suggest that PI-3K/Akt pathway may not play a major role in apoptosis induced by RSVL in MDA231 cells.

To study the time course of ERK activation and apoptosis, MDA231 cells were treated with either vehicle or $50 \mu \mathrm{M}$ of RSVL and were harvested at indicated time-points (1, 3, 6, 8, $10,12,16$ and $24 \mathrm{~h}$ ) for Western blot analysis. Significant activation of ERK was observed only after 10-h exposure to RSVL and remained highly activated through the course of experiment $(24 \mathrm{~h})$. Cleavage of PARP was detected after $16 \mathrm{~h}$ and detected at high levels after $24 \mathrm{~h}$ of treatment. Suppression of Bcl-2 occurred as early as $10 \mathrm{~h}$ after RSVL treatment (Fig. 3A), when apoptosis is not detected. This suggests that the sustained activation of ERK and suppression of Bcl-2 may trigger apoptosis induced by RSVL.

To study the role of apoptotic cell death induced by RSVL, cells were pretreated with the pan-caspase inhibitor Z-VAD-FMK followed by RSVL treatment. Pretreatment with Z-VAD-FMK resulted in complete blockage of inhibitory effects of RSVL on cell growth (data not shown) and cleavage of caspase-3 and PARP (Fig. 3B), indicating that apoptosis is the main mechanism of cell death following RSVL treatment. Although co-treatment with caspase inhibitor inhibited apoptosis induced by RSVL, it did not affect phosphorylation of ERK1/2 (Fig. 3B). The data further suggest that ERK1/2 acts upstream of caspase- 3 to exert its apoptotic influence on the RSVL-treated MDA231 cells.

To investigate if RSVL-induced apoptosis is mediated by ERK activation, MDA231 cells were treated with UO126, a well-known inhibitor of MEK1/2, a signaling molecule directly upstream of ERK1/2, to block ERK1/2 activation and its downstream substrates. Nuclear staining with DAPI showed that RSVL treatment induced DNA condensation and fragmentation by $69.4 \%$ while co-treatment of UO126 and RSVL significantly reduced the DNA fragmentation (to $11.3 \%$, $\mathrm{p}<0.01$ ) (Fig. 4A). The results were further strengthened by Western blot data, which show that RSVL at 10 and $50 \mu \mathrm{M}$ alone increased ERK1/2 phosphorylation, caspase-3 and PARP cleavage, while co-treatment with UO126 almost completely blocked the activation of ERK1/2, and cleavage of caspase-3 and PARP induced by RSVL (Fig. 4B). To further investigate the possible mechanism of this prevention of apoptosis, the same blot was used to probe with Bcl-2, Bcl-XL, Bax, Bad and Bim antibodies. Interestingly, blocking MEK/ERK signaling does not only abrogate the actions of RSVL to suppress Bcl-2, but in fact increases the protein level of Bcl-2 


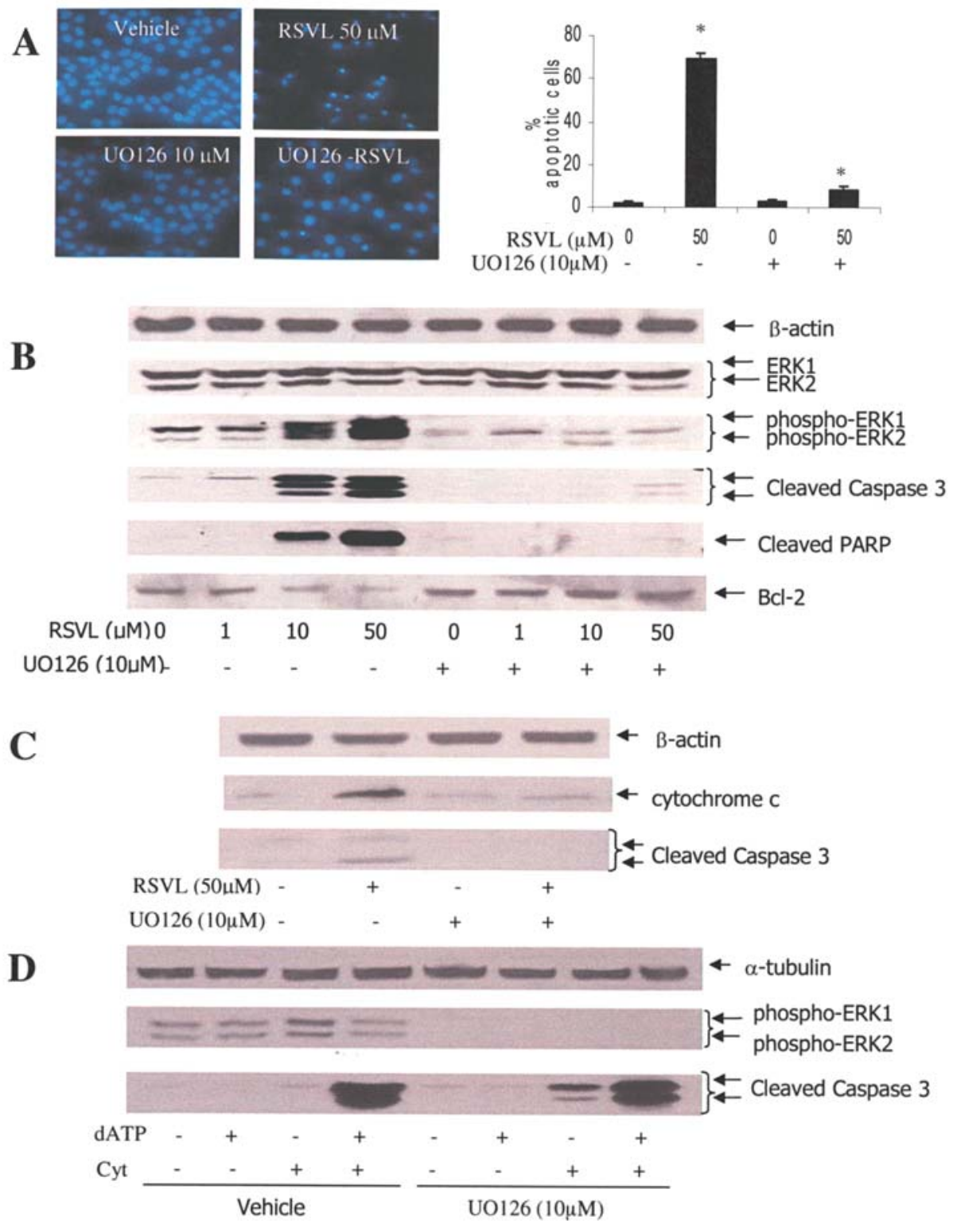

Figure 4. Effects of UO126 on RVSL-induced apoptosis in MDA231 cells. A, Inhibition of ERK1/2 by UO126 abolished RSVL-induced apoptosis. Cells were treated with vehicle, $50 \mu \mathrm{M}$ of RSVL, $10 \mu \mathrm{M}$ of UO126, and $50 \mu \mathrm{M}$ of RSVL and $10 \mu \mathrm{M}$ of UO126 for $24 \mathrm{~h}$. DNA fragmentation was assessed as described in Materials and methods and Fig. 1. ${ }^{*}$ p $<0.01$ when compared with vehicle control (ANOVA). Representative images from three different experiments with similar results are shown. B, Effects of MEK1/2 inhibitor UO126 on phosphorylation of ERK1/2, cleavage of caspase-3 and PARP, Bcl-2 expression. Cells were treated with indicated concentrations of RSVL alone or in combination with UO126 for $24 \mathrm{~h}$ and lysed for Western blot analysis as described. Blots were probed with antibodies against phospho-ERK1/2, ERK1/2, cleaved caspase-3, cleaved PARP and Bcl-2. C, Release of cytochrome c into cytosol during treatment with RSVL and UO126. S-100 fractions extracted from cells treated with $50 \mu \mathrm{M}$ of RSVL and $10 \mu \mathrm{M}$ of UO126 both alone or in combination were subjected to Western blotting to detect cytochrome $\mathrm{c}$ and cleaved caspase-3. D, Induction of in vitro apoptosis using dATP and bovine cytochrome $\mathrm{c}$. S-100 fractions $(50 \mu \mathrm{g})$ from vehicle- or UO126-treated cells were incubated with dATP (1 mM) and/or bovine cytochrome c (0.3 $\mu \mathrm{g})$ and subjected to Western blotting for detection of caspase-3 cleavage and phospho-ERK1/2. Experiments were repeated three times with similar results.

(Fig. 4B). Neither RSVL nor UO126 treatment had any effect on the levels of Bax and Bad expression. Bim was not detectable under experiment conditions (data not shown). The data indicate that activation of ERK $1 / 2$ is critical for apoptosis induced by RSVL and its possible role in suppressing Bcl-2 expression.

Since it has been reported that Bcl-2 is located on the outer membrane of mitochondria and plays an important role in the release of cytochrome $\mathrm{c}$, which is necessary for the initiation of the apoptotic process (31), we hypothesized that RSVL may induce apoptosis by regulating $\mathrm{Bcl}-2$ expression through ERK1/2 activation and thus the upregulation of Bcl-2 following incubation with UO126 may be involved in the release of cytochrome c. To address this hypothesis, cytosolic proteins (S-100) extracted with the protection of mitochondria (as described in Materials and methods) from control and RSVL-treated cells were analysed. As predicted, cytochrome $\mathrm{c}$ was released to the cytosol following RSVL treatment and the release was inhibited when cells treated with either UO126 or combination of UO126 and RSVL (Fig. 4C). The data suggest that RSVL induces apoptosis by regulating Bcl-2 expression through ERK1/2 activation. 

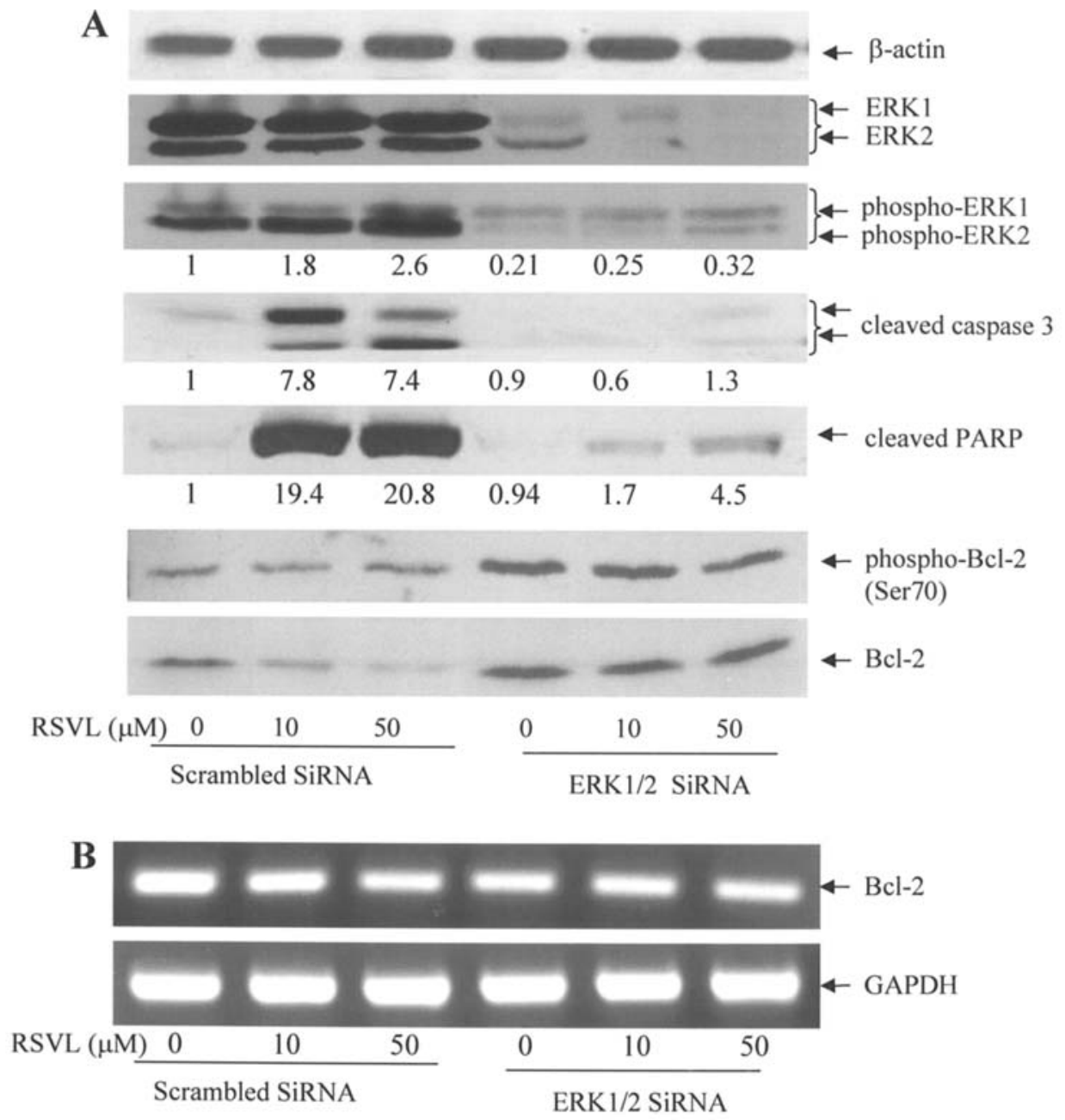

Figure 5. Silencing ERK1/2 by SiRNA affects RSVL-induced apoptosis and Bcl-2 expression in MDA231 cells. A, ERK1/2 SiRNA transfection inhibits RSVL-induced apoptosis and upregulates Bcl-2 and its phosphorylated form at Ser70. MDA231 cells were transfected with scrambled or a mixture of specific SiRNAs against ERK1/2 and treated with indicated concentrations of RSVL. Cells were harvested and performed total cell lysis for Western blot analysis as described in Materials and methods. Blots were probed with antibodies against phospho-ERK1/2, ERK1/2, cleaved caspase-3, cleaved PARP, phospho-Bcl-2 (Ser70) and Bcl-2. Representative blots of three experiments with similar results are shown. B, RSVL treatment and ERK1/2 SiRNA transfection inbibits the mRNA level of Bcl-2. Total RNA was extracted after cells transfected with scrambled or specific SiRNAs against ERK1/2 and treated with indicated concentrations of RSVL. One-step RT-PCR was performed to detect the mRNAs of Bcl-2 and GAPDH as described in Materials and methods. Experiments were repeated two times with similar results.

To address the question if ERK1/2 may directly affect caspase-3 cleavage as previously suggested (reviewed in ref. 21), S-100 fractions extracted from the vehicle or UO126treated cells (for $3 \mathrm{~h}$ ) were used to induce in vitro apoptosis using dATP and cytochrome c. As shown in Fig. 4D, phosphorylated ERK1/2 were undetectable after 3-h treatment with UO126 and in the presence of dATP and cytochrome c, cleavage of caspase- 3 was observed virtually equally in both S-100s of vehicle and UO126 treated cells. Cleavage of caspase-3 was observed at a low level when only cytochrome c was added to the cytosol from UO126- treated cells. The results suggest that ERK1/2 may not directly affect caspase-3 cleavage during apoptosis.

Recent studies suggested that biological actions previously thought to be responsible by ERK1/2 might, in fact, be mediated by MEK5/ERK5 signaling as UO-126 and PD98059, another MEK1 inhibitor, inhibit ERK1/2 as well as ERK5 $(32,33)$. To determine if ERK $1 / 2$ activation is specifically required for apoptosis induced by RSVL, specific knockdown of ERK1/2 by SiRNA was employed for this study. As predicted, silencing ERK1/2 inhibits the cleavage of caspase-3 and PARP (Fig. 5A). Furthermore, upregulation of Bcl-2 protein was also observed when ERK1/2 was silenced. As phosphorylation of Bcl-2 at Ser70 has been shown to be critical for its anti-apoptotic functioning (34), we wished to study this specific phosphorylation site. The same set of samples was blotted with phospho-Bcl-2 (Ser70) antibody. The result showed that knockdown of ERK1/2 upregulated phospho-Bcl-2 (Ser70) (Fig. 5A). Interestingly, RT-PCR of Bcl-2 showed that inhibition of ERK1/2 activity by UO126 (data not shown) or SiRNA slightly reduced the mRNA level of Bcl-2 (Fig. 5B), suggesting that abrogation of ERK1/2 activity might induce phosphorylation of Bcl-2 at Ser70 and this, in turn, stabilizes the $\mathrm{Bcl}-2$ protein.

Since previous studies including ours have suggested that duration and amplitude of ERK activation may be important in apoptosis induced by anticancer drugs $(22,23,26)$, we determined if the intensity of this constitutively active signaling would affect cell sensitivity to RSVL. MDA231 cells were stably transfected with either empty vector pMCL (mock) or 
A

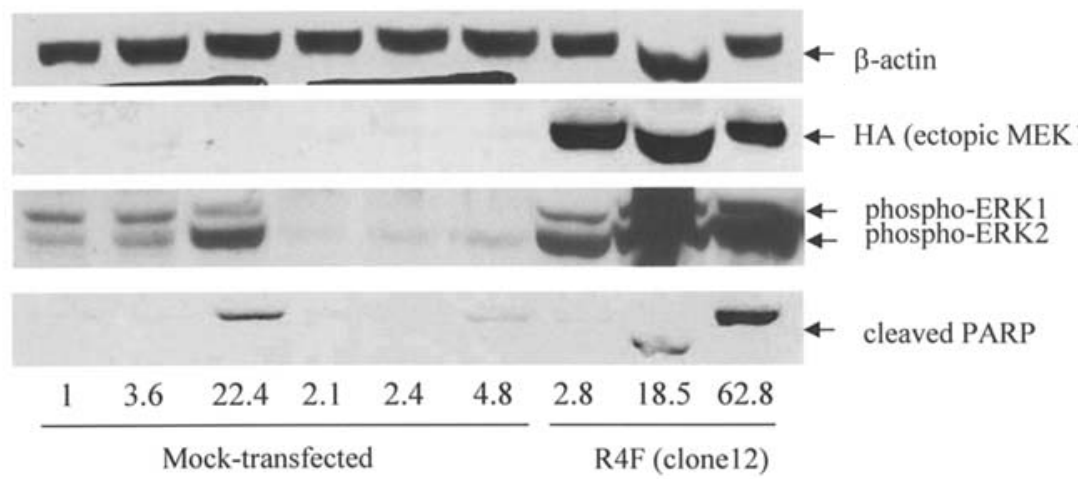

B
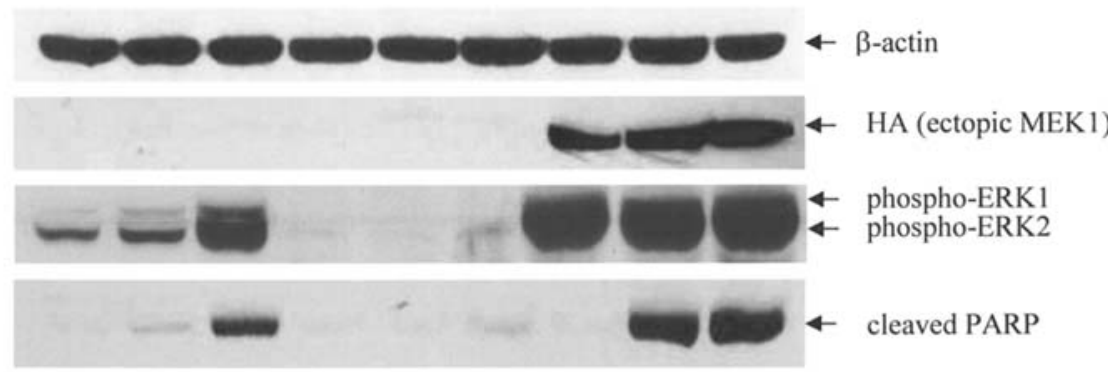

\begin{tabular}{lllllllll}
1 & 4.1 & 40.4 & 1.5 & 1.9 & 5.0 & 2.7 & 60.9 & 66.3 \\
\hline
\end{tabular}

\begin{tabular}{lcccccccccc}
\multicolumn{4}{c}{ Mock-transfected } & \multicolumn{4}{c}{ R4F (clone 18) } \\
$\operatorname{UO126}(10 \mu \mathrm{M})-$ & - & - & + & + & + & - & - & - \\
$\operatorname{RSVL}(\mu \mathrm{M})$ & 0 & 10 & 50 & 0 & 10 & 50 & 0 & 10 & 50
\end{tabular}

Figure 6. Effects of inhibition of ERK1/2 by UO126 and of enforced activation of ERK1/2 by constitutively expressed MEK1 construct on RSVL-induced cleavage of PARP in MDA231 cells. Mock-transfected MDA231 cells were treated with RSVL and or UO126; two clones of stably transfected MEK1 R4F12 (A) and R4F18 (B) (which show the highest expression of MEK1 and activation of ERK) were treated with RSVL and total cell lysate was prepared for Western blot analysis as described in Materials and methods. Blots were probed with antibodies against phospho-ERk1/2, HA and cleaved PARP. The numbers below each blot refer to the fold change of cleaved PARP after being normalized to the level of $\beta$-actin. Representative blots of three experiments with similar results are shown.

pMCL-HA-MEK1 (R4F), which constitutively expresses MEK1 and activates both ERK1 and ERK2 (17). The mock transfected and two clones of constitutively activated MEK1transfected cells (R4F12 and R4F18, which have the high expression level of MEK1 and phospho-ERK1/2) were treated with either vehicle, 10 or $50 \mu \mathrm{M}$ of RSVL for $20 \mathrm{~h}$ and harvested for Western blot analysis. Fig. 6 shows that at 20-h incubation, a very low level of cleaved PARP was detected in RSV-treated mock-transfected MDA231 cells by Western blotting, while much higher level of and cleaved PARP was detected in the two MEK1-transfected clones R4F12 (Fig. 6A) and R4F18 (Fig. 6B). Especially, at the low concentration of $10 \mu \mathrm{M}$ of RSVL, significant amounts of cleaved caspase-3 and cleaved PARP were seen in the RSVL-treated MEK-1 transfected cells, which were not clearly detected in the RSVL-treated mock-transfected cells. Combined treatment of UO126 and RSVL inhibited PARP cleavage and DNA fragmentation (data not shown). In addition, MEK-1 transfected cells exhibited more DNA fragmentation than the mock-transfected cells when treated with RSVL (data not shown). These data further support the critical role of activation of MEK/ERK pathway in RSVL-induced apoptosis in MDA231 cells.

\section{Discussion}

In this study, we demonstrated that RSVL inhibits cell proliferation and induces apoptosis in highly invasive breast cancer MDA231 cells and this is critically regulated by the activation of ERK1/2. Our data suggest that in addition to promoting apoptosis, ERK1/2 activities could play an important role in regulating $\mathrm{Bcl}-2$ expression through phosphorylation that tilts the balance of mitochondrial anti-apoptotic and proapoptotic proteins and eventually leads to cell death induced by RSVL in MDA231 cells.

RSVL has been shown to inhibit cell growth and proliferation in a variety of cancer cell lines by causing cell cycle arrest and apoptosis $(13,15,16,29)$. Our study aimed at elucidating the possible mechanisms of apoptosis induced by RSVL in MDA231 highly metastatic breast cancer cells. Two major distinct apoptotic pathways for mammalian cells have been described (35). A previous study suggested that RSVL could trigger death receptors by clustering of Fas and its redistribution and result in activation of the initiator caspase-8, which can propagate the apoptosis signal by direct cleavage of downstream effector caspases such as caspase- 3 in other cells (36). However, we did not observe any significant change in caspase- 8 and Bid expression. Cleaved caspase- 8 
and truncated Bid were also not detected (data not shown). Therefore, it is unlikely that apoptosis in MDA231 cells was initiated by triggering death receptors. We did not observe a significant difference in Bad expression and its phosphorylated forms at Ser112 and Ser136, suggesting that Bad may not be important for RSVL-induced apoptosis in MDA231 cells, neither was any difference in Bax expression detected. Although the precise role of Bax was not examined in this study, Bax redistribution from its predominantly cytosol location to mitochondrial membrane, but not its expression has been shown to play a role in inducing the release of cytochrome c (37). Moreover, administration of RSVL significantly suppresses the anti-apoptotic protein Bcl-2. Overall, there is a shift in the ratio of pro-apoptotic and antiapoptotic proteins following RSVL treatment. It is possible that inhibition of Bcl-2 by RSVL allows more Bax to translocate to the mitochondrial membrane and induces the membrane permeability transition, a critical event for apoptosis (reviewed in ref. 38). The suppression of Bcl-2 also allows more free apoptosis-activating factor (Apaf-1) to trigger the release of cytochrome $c$, which is required to activate the two death proteases, caspases-9 and -3 (39). Two closely related proteins of $\mathrm{Bcl}-2$ were observed unchanged (Bcl-XL) or undetectable (Bim). Although contribution of other anti- and pro-apoptotic proteins was not examined in this study, the evidence of apoptosis and suppression of Bcl-2 could suggest that there may be a shift that tilts the balance between the anti-apoptotic and pro-apoptotic proteins favoring apoptosis following RSVL treatment. Although the relationship between Bcl-2 and ERK activation has been implicated in many studies and growth factor-regulated pro-survival ERK1/2 has been shown to upregulate $\mathrm{Bcl}-2$ expression, it is not known if proapoptotic activity of ERK $1 / 2$ regulates Bcl-2 functions. In this study, suppression of Bcl-2 by RSVL is reversed by inhibition of ERK1/2 by both UO126 and SiRNA. Moreover, inhibition or knockdown of ERK1/2 slightly decreases the transcript level of Bcl-2 but increases the Bcl-2 protein and its phosphorylated form at Ser70, suggesting that the posttranslational modification at Ser70 may render Bcl-2 more stable and thus enhance its anti-apoptotic function. The data are supported by previous study showing that phosphorylation of Bcl-2 at Ser70 is required for antiapoptotic functioning of Bcl-2 (34). The data also suggest ERK1/2 activation by RSVL contributes to the suppression of $\mathrm{Bcl}-2$ function. This result is similar to that observed by $\mathrm{Xu}$ et al that transfection of dominant negative ERK2 reversed the Bcl-2 suppression elicited by many highly effective antitumor isothiocyanates in prostate cancer cells (41). It remains to be determined how ERK inhibition upregulates posttranslational modification of Bcl-2 at Ser70 and if ERK1/2 activation during RSVL treatment affects the degradation of Bcl-2.

Previous studies have demonstrated that the other two closely related members of ERK1/2, p38 MAPK and SAPK/ JNK might be associated with cell proliferation or apoptosis depending on the cell types and stimuli (41-44). In this study, we did not observe any significant change of p38 MAPK and JNK activities after RSVL treatment in MDA231 cells. Moreover, our unpublished data showed that pretreatment with specific p38 MAPK inhibitor or JNK inhibitor neither prevented nor enhanced significantly apoptosis induced by RSVL. Therefore, it is unlikely that p38 MAPK or JNK signaling participates in RSVL-induced cell death of MDA231 cells.

Our study demonstrates that ERK1/2 activation plays a critical role in the cleavage of executive caspase- 3 and PARP, which is central in the process of cell death induced by RSVL in MDA231 cells. It is important to note that there are different mechanisms of ERK activation. While ERK activation induced by growth factors could be rapid (occurring within minutes) and transient, it can also be sustained depending on the stimuli. With RSVL, no significant activation occurs until $10 \mathrm{~h}$, and the activity remains highly elevated through the remaining time period examined $(24 \mathrm{~h})$. It is worthy to note that cells were treated in SFM conditions in which no interfering factors, which are usually found in the serum, would affect the ERK pathway. It has been reported that RSVL binds to cell surface receptor integrin $\alpha \mathrm{V} \beta 3$ and activates ERK signaling through this receptor in breast cancer cells (29). Activation of ERK1/2 occurred before apoptosis could be detected and remains highly activated while cells were undergoing the intensified stage of apoptosis. This could suggest that the activation of ERK either signals or is required for the cleavage of executive caspases. Utilizing the specific inhibitor UO126 and SiRNAs against ERK1/2 to modulate the ERK activity, we found that the inhibition of ERK1/2 activation significantly reduced RSVL-induced cytochrome c release and cleavage of caspase-3 and PARP. Especially, inhibition of ERK reverts the RSVL-induced suppression of $\mathrm{Bcl}-2$, which has been shown to be able to prevent apoptotic cell death (45) and increases the phosphorylation of Bcl-2 at Ser70, which was shown to be critical for its anti-apoptotic action (34). Our data also showed that cell free extracts from UO126 treated cells exhibited an equal cleavage of caspase-3 compared with vehicle-treated cells when inducing in vitro apoptosis using dATP and cytochrome c as previously described (27). Similar data were observed when using other techniques to remove ERK activity in the cytosol (S-100) of MDA231 cells (immuno-depleted, SiRNA transfection) before inducing in vitro apoptosis (data not shown). Thus, the data suggest that ERK activity may be required for suppressing anti-apoptotic functioning of Bcl-2 protein through its phosphorylation at Ser70, which leads to the release of cytochrome $c$ and caspase- 3 activation, rather than directly affecting caspase-3 cleavage as previously suggested (reviewed in ref. 21). This finding further emphasized the importance of ERK1/2 activation and its activity in RSVLinduced apoptosis of MDA231 cells by suppressing Bcl-2 and caspase-3 activation. Our results support the proapoptotic role of ERK1/2 during drug treatment and are in agreement with previous studies, which demonstrated that ERK activation is required for cisplatin-induced apoptosis in HeLa and A549 cells (46) and abrogation of ERK pathway prevents RSVLinduced apoptosis in human osteosarcoma SJSA1 cells (47). We also showed that transfection of the constitutively expressed MEK1, which activates both ERK1 and ERK2, renders the cells more invasive and able to survive longer in serum-free media ( $>48 \mathrm{~h}$ ) than the mock-transfected cells (data not shown). This result is supported by the previous report that MEK1 transfected cells become more invasive 
and metastasized and highly metastatic breast cancer cells have higher constitutive activity of ERK compared to less invasive cancer cells (18). Moreover, constitutively active ERK has been shown to contribute to cell growth, proliferation, migration and transformation (17,18). Surprisingly, MEK1 transfected cells become more sensitive to RSVL-induced apoptosis. The mechanisms by which these highly invasive cells become more responsive to RSVL are unclear. However, it suggests that ERK activity could play a central role in apoptosis induced by RSVL in these cells. Similarly, RSVL could act more effectively on the highly proliferative cells. This highly proliferative cell-targeting property of RSVL is further supported by previous studies showing that RSVL does not induce apoptosis in normal cells treated at very high concentrations (48) but extremely effective against the highly invasive breast cancer cell line MDA-MB-435 (15). The ability of ERK to regulate cell death and proliferation appears to depend on cell types, timing of activation, duration of its activation, amplitude of its activity and the agents, which signal the activation. In this study, highly active status of ERK1/2 renders cells more vulnerable to RSVL exposure. The possible stabilization of Bcl-2 through its phosphorylation at Ser70 when ERK1/2 is inhibited suggests that the highly active status of ERK1/2 could render cells more sensitive to ERK-activating agents. The questions remaining are how posttranslational modification of bcl-2 at Ser70 is regulated by ERK $1 / 2$, whether ERK $1 / 2$ activity and its activation during RSVL treatment involved in Bcl-2 degradation, and what specifies cell death rather than survival when ERK1/2 activated.

In conclusion, this study contributes to clarification of the pro-apoptotic role of ERK1/2 in cancer treatment. Since many powerful anticancer drugs also activate ERK signaling and exert their functions through ERK activation $(26,46,49)$ and a combination may need to be considered for treatment of cancer, especially of metastatic tumors, it raises the possibility that RSVL could act in synergy with these compounds in treatment of highly invasive, metastatic and unresponsive breast cancer.

\section{Acknowledgements}

This work was supported by grants from the National Medical Research Council (NMRC) of Singapore (R-185-000-105-213) to Lina Hsiu Kim Lim. We would like to thank Professor Natalie Ahn (University of Colorado, Boulder, CO) for generously providing us the pMCL-HA-MEK1 construct.

\section{References}

1. Madigan MP, Ziegler RG, Benichou J, Byrne C and Hoover RN: Proportion of breast cancer cases in the united states explained by well-established risk factors. J Natl Cancer Inst 87: 1681-1685, 1995.

2. Tabar L, Fagerberg G, Day NE, Duffy SW and Kitchin RM: Breast cancer treatment and natural history: new insights from results of screening. Lancet 339: 412-414, 1992.

3. Greenberg PA, Hortobagyi GN, Smith TL, Ziegler LD, Frye DK and Buzdar AU: Long-term follow-up of patients with complete remission following combination chemotherapy for metastatic breast cancer. J Clin Oncol 14: 2197-2205, 1996.

4. Howe GR, Hirohata T, Hislop TG, et al: Dietary factors and risk of breast cancer: combined analysis of 12 case-control studies. $\mathrm{J}$ Natl Cancer Inst 82: 561-569, 1990.
5. Waladkhani AR and Clemens MR: Effect of dietary phytochemicals on cancer development (Review). Int J Mol Med 1: 747-753, 1998.

6. Martin KR: Targeting apoptosis with dietary bioactive agents. Exp Biol Med 231: 117-129, 2006.

7. Jang M, Cai L, Udeani GO, et al: Cancer chemopreventive activity of resveratrol, a natural product derived from grapes. Science 275: 218-220, 1997.

8. Baur JA and Sinclair DA: Therapeutic potential of resveratrol: the in vivo evidence. Nat Rev Drug Discov 5: 493-506, 2006.

9. Holme AL and Pervaiz S: Resveratrol in cell fate decisions. J Bioenerg Biomembr 39: 59-63, 2007.

10. Pervaiz S: Chemotherapeutic potential of the chemopreventive phytoalexin resveratrol. Drug Resist Update 7: 333-344, 2004.

11. Bowers JL, Tyulmenkov VV, Jernigan SC and Klinge CM: Resveratrol acts as a mixed agonist/antagonist for estrogen receptors alpha and beta. Endocrinology 141: 3657-3667, 2000 .

12. Gehm BD, McAndrews JM, Chien PY and Jameson JL: Resveratrol, a polyphenolic compound found in grapes and wine, is an agonist for the estrogen receptor. Proc Natl Acad Sci USA 94: 14138-14143, 1997 .

13. Lu R and Serrero G: Resveratrol, a natural product derived from grape, exhibits antiestrogenic activity and inhibits the growth of human breast cancer cells. J Cell Physiol 179: 297-304, 1999.

14. Clement MV, Hirpara JL, Chawdhury SH and Pervaiz S: Chemopreventive agent resveratrol, a natural product derived from grapes, triggers CD95 signaling-dependent apoptosis in human tumor cells. Blood 92: 996-1002, 1998.

15. Hsieh TC, Burfeind P, Laud K, et al: Cell cycle effects and control of gene expression by resveratrol in human breast carcinoma cell lines with different metastatic potentials. Int J Oncol 15: 245-252, 1999.

16. Garvin S, Ollinger K and Dabrosin C: Resveratrol induces apoptosis and inhibits angiogenesis in human breast cancer xenografts in vivo. Cancer Lett 231: 113-122, 2006.

17. Mansour SJ, Matten WT, Hermann AS, et al: Transformation of mammalian cells by constitutively active MAP kinase kinase. Science 265: 966-970, 1994.

18. Krueger JS, Keshamouni VG, Atanaskova N and Reddy KB: Temporal and quantitative regulation of mitogen-activated protein kinase (MAPK) modulates cell motility and invasion. Oncogene 20: 4209-4218, 2001.

19. Chang F, Steelman LS, Lee JT, et al: Signal transduction mediated by the Ras/Raf/MEK/ERK pathway from cytokine receptors to transcription factors: potential targeting for therapeutic intervention. Leukemia 17: 1263-1293, 2003.

20. Kolch W, Kotwaliwale A, Vass K and Janosch P: The role of raf kinases in malignant transformation. Expert Rev Mol Med 2002: 1-18, 2002.

21. Zhuang S and Schnellmann RG: A death-promoting role for extracellular signal-regulated kinase. J Pharmacol Exp Ther 319: 991-997, 2006.

22. Ishikawa $Y$ and Kitamura M: Dual potential of extracellular signal-regulated kinase for the control of cell survival. Biochem Biophys Res Commun 264: 696-701, 1999.

23. Shih A, Davis FB, Lin HY and Davis PJ: Resveratrol induces apoptosis in thyroid cancer cell lines via a MAPK- and p53dependent mechanism. J Clin Endocrinol Metab 87: 1223-1232, 2002.

24. Qiao D, Stratagouleas ED and Martinez JD: Activation and role of mitogen-activated protein kinases in deoxycholic acidinduced apoptosis. Carcinogenesis 22: 35-41, 2001

25. McCubrey JA, Steelman LS, Chappell WH, et al: Roles of the Raf/MEK/ERK pathway in cell growth, malignant transformation and drug resistance. Biochim Biophys Acta 1773: 1263-1284, 2007.

26. Nguyen TT, Tran E, Nguyen TH, Do PT, Huynh TH and Huynh H: The role of activated MEK-ERK pathway in quercetin-induced growth inhibition and apoptosis in A549 lung cancer cells. Carcinogenesis 25: 647-659, 2004.

27. Nguyen TH, Ong CK, Wong E, Leong CT, Panasci L and Huynh H: 2-Chloroethyl-3-S arcosinamide-1-Nitrosourea (SarCNU) exhibits p53-dependent and -independent antiproliferative activity in human nasopharyngeal carcinoma cells in vitro and in vivo. Int J Oncol 27: 1131-1140, 2005.

28. Liu X, Kim CN, Yang J, Jemmerson R and Wang X: Induction of apoptotic program in cell-free extracts: requirement for dATP and cytochrome c. Cell 86: 147-157, 1996. 
29. Boise LH, Gonzalez-Garcia M, Postema CE, et al: Bcl-x, a Bcl-2related gene that functions as a dominant regulator of apoptotic cell death. Cell 74: 597-608, 1993.

30. Lin HY, Lansing L, Merillon JM, et al: Integrin alphaVbeta3 contains a receptor site for resveratrol. FASEB J 20: 1742-1744, 2006.

31. Aziz MH, Nihal M, Fu VX, Jarrard DF and Ahmad N: Resveratrol-caused apoptosis of human prostate carcinoma LNCaP cells is mediated via modulation of phosphatidylinositol 3'-kinase/AKT pathway and Bcl-2 family proteins. Mol Cancer Ther 5: 1335-1341, 2006.

32. Kluck RM, Bossy-Wetzel E, Green DR and Newmeyer DD: The release of cytochrome $\mathrm{c}$ from mitochondria: a primary site for bcl-2 regulation of apoptosis. Science 275: 1132-1136, 1997.

33. Kamakura S, Moriguchi T and Nishida E: Activation of the protein kinase ERK5/BMK1 by receptor tyrosine kinases. identification and characterization of a signaling pathway to the nucleus. J Biol Chem 274: 26563-26571, 1999.

34. Kato Y, Chao TH, Hayashi M, Tapping RI and Lee JD: Role of BMK1 in regulation of growth factor-induced cellular responses. Immunol Res 21: 233-237, 2000.

35. Ito T, Deng X, Carr B and May WS: Bcl-2 phosphorylation required for anti-apoptosis function. J Biol Chem 272: 1167111673, 1997.

36. Ghobrial IM, Witzig TE and Adjei AA: Targeting apoptosis pathways in cancer therapy. CA Cancer J Clin 55: 178-194, 2005.

37. Delmas D, Rebe C, Lacour S, et al: Resveratrol-induced apoptosis is associated with fas redistribution in the rafts and the formation of a death-inducing signaling complex in colon cancer cells. J Biol Chem 278: 41482-41490, 2003.

38. Wolter KG, Hsu YT, Smith CL, Nechushtan A, Xi XG and Youle RJ: Movement of bax from the cytosol to mitochondria during apoptosis. J Cell Biol 139: 1281-1292, 1997.

39. Chao DT and Korsmeyer SJ: BCL-2 family: regulators of cell death. Annu Rev Immunol 16: 395-419, 1998.

40. Zou H, Henzel WJ, Liu X, Lutschg A and Wang X: Apaf-1, a human protein homologous to $C$. elegans CED-4, participates in cytochrome c-dependent activation of caspase-3. Cell 90: 405-413, 1997.
41. Xu C, Shen G, Yuan X, et al: ERK and JNK signaling pathways are involved in the regulation of activator protein 1 and cell death elicited by three isothiocyanates in human prostate cancer PC-3 cells. Carcinogenesis 27: 437-445, 2006.

42. Xia Z, Dickens M, Raingeaud J, Davis RJ and Greenberg ME: Opposing effects of ERK and JNK-P38 MAP kinases on apoptosis. Science 270: 1326-1331, 1995.

43. Frasch SC, Nick JA, Fadok VA, Bratton DL, Worthen GS and Henson PM: P38 mitogen-activated protein kinase-dependent and -independent intracellular signal transduction pathways leading to apoptosis in human neutrophils. J Biol Chem 273: 8389-8397, 1998

44. Sanchez-Prieto R, Rojas JM, Taya Y and Gutkind JS: A role for the P38 mitogen-acitvated protein kinase pathway in the transcriptional activation of p53 on genotoxic stress by chemotherapeutic agents. Cancer Res 60: 2464-2472, 2000.

45. Tsuruta F, Sunayama J, Mori Y, et al: JNK promotes Bax translocation to mitochondria through phosphorylation of 14-3-3 proteins. EMBO J 23: 1889-1899, 2004.

46. Yang J, Liu X, Bhalla K and et al: Prevention of apoptosis by Bcl-2: release of cytochrome c from mitochondria blocked. Science 275: 1129-1132, 1997.

47. Wang X, Martindale JL and Holbrook NJ: Requirement for ERK activation in cisplatin-induced apoptosis. J Biol Chem 275: 39435-39443, 2000.

48. Alkhalaf $M$ and Jaffal S: Potent antiproliferative effects of resveratrol on human osteosarcoma SJSA1 cells: novel cellular mechanisms involving the ERK/P53 cascade. Free Radic Biol Med 41: 318-325, 2006.

49. Aggarwal BB, Bhardwaj A, Aggarwal RS, Seeram NP, Shishodia $S$ and Takada Y: Role of resveratrol in prevention and therapy of cancer: preclinical and clinical studies. Anticancer Res 24: 2783-2840, 2004.

50. Miglietta A, Bozzo F, Bocca C, Gabriel L, Trombetta A, Belotti S and Canuto RA: Conjugated linoleic acid induces apoptosis in MDA-MB-231 breast cancer cells through ERK/MAPK signalling and mitochondrial pathway. Cancer Lett 234: 149-157, 2006. 